\title{
PSEUDOANAPLECTINIA YUMOTOI, A NEW \\ OVOVIVIPAROUS MYRMECOPHILOUS COCKROACH \\ GENUS AND SPECIES FROM SARAWAK \\ (BLATTARIA: BLATTELLIDAE; BLATTELLINAE)
}

\author{
By Louis M. Roth \\ Museum of Comparative Zoology \\ Harvard University \\ Cambridge, MA 02138, U.S.A.*
}

\begin{abstract}
Pseudoanaplectinia yumotoi, a new myrmecophilous cockroach genus and species, is described from Sarawak. Based on the male genital phallomeres, it is placed in the Blattellidae: Blattellinae. The genus is ovoviviparous and probably arose from an anaplectinoid-like ancestor. This is the third case of ovoviviparity arising in the Blattellidae. The cockroach has a symbiotic relationship with an ant Crematogaster sp.
\end{abstract}

\section{INTRODUCTION}

Dr. Takakazu Yumoto is involved in a Canopy Biology Program in Sarawak and is studying the relationship between epiphytes and animals. He found that a large number of cockroaches live on a fern in association with a species of ant (Crematogaster sp.), and he will publish a detailed study of the epiphyte-cockroach-ant relationship elsewhere.

The new cockroach is ovoviviparous, making this the third case of a blattellid genus (Blattellinae, because its ootheca is rotated before being retracted into the uterus, and the male's genital hook is on the left side) that evolved ovoviviparity. The other ovoviviparous blattellid genera are Stayella Roth (Blattellinae) from Africa (Roth, 1982; 1984) and Sliferia Roth (Pseudophyllodromiinae, because the ootheca is not rotated before being retracted internally,

*Correspondence: 81 Brush Hill Road, P.O. Box 540, Sherborn, MA 01770, U.S.A.

Manuscript received 27 November 1995. 
and the male's genital hook is on the right side) from the Seychelles (Roth, 1989; 1996a).

In this paper I describe the cockroach that occurs in the above association with ants. The holotype and paratypes are deposited in the Museum of Comparative Zoology, Harvard University (MCZ). A pair of adult paratypes has been deposited in the following museums: Hope Entomological Collections, Oxford, England (HECO); the Academy of Natural Sciences of Philadelphia (ANSP); Naturhistoriska Riksmuseet, Stockholm, Sweden (NRSS); Naturhistorisches Museum zu Wien, Vienna, Austria (NMVA); and Rijksmuseum van Natuurlijke Historie, Leiden, The Netherlands (RNHL).

\section{Pseudoanaplectinia, new genus}

Diagnosis: Very small. Tegmina and wings present, reduced (smaller in the female), not reaching the end of the abdomen. Hind wing (Fig. 7), male subgenital plate and genitalia (Fig. 1) blattellid-anaplectoid-like. Antennae reduced, reaching to about the middle of the abdomen. Legs reduced in length; all femora with only two, three, or four large distal spines on antero- and posteroventral margins; pulvilli absent, tarsal claws symmetrical, their ventral margins minutely serrated, arolia minute (Fig. 2). Cerci segmented, short, not reaching beyond supraanal plate (Fig. 4). Male seventh abdominal tergum specialized (Fig. 4). Male genital hook on the left side (Fig. 1). Female subgenital plate not valvular. Ovoviviparous; ootheca (Fig. 3) with three to five eggs in a membranous, transparent egg case, carried internally, with the keel region directed to the left side of the female.

\section{Pseudoanaplectinia yumotoi, new species}

Material: Holotype, ơ, Sarawak, Lambir Hills National Park, ix.1995, T. Yumoto, collected in association with an ant Crematogaster sp. living on an epiphyte, Platycerium coronarium (Koenig) Desv., a stag's horn fern; Type No. 34763 in MCZ. Paratypes. MCZ: same data as holotype, 370"0", 28@o, 69 nymphs, 7 oothecae (adult legs and male terminalia on slides 295 and 296, the pinned specimens destroyed). 


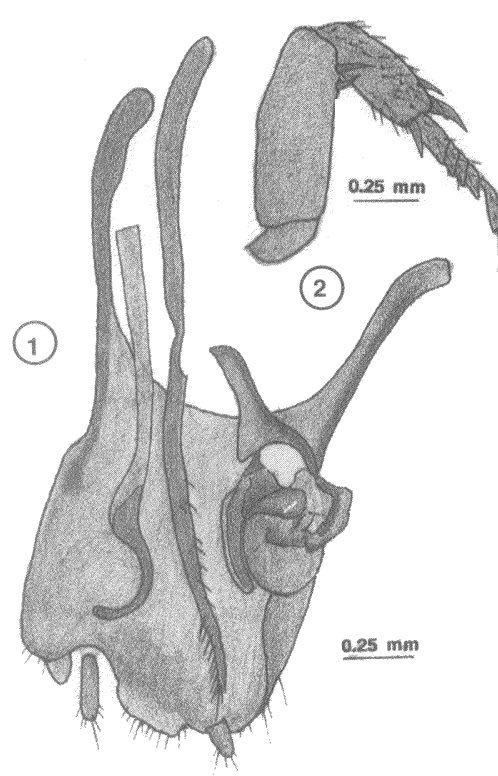

(3)
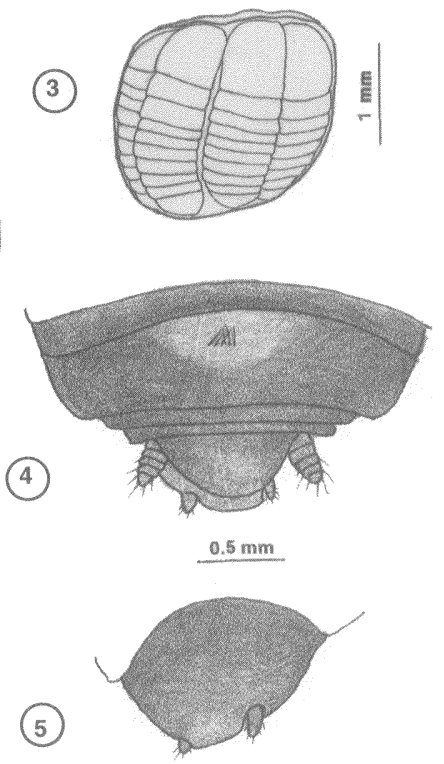

(6)
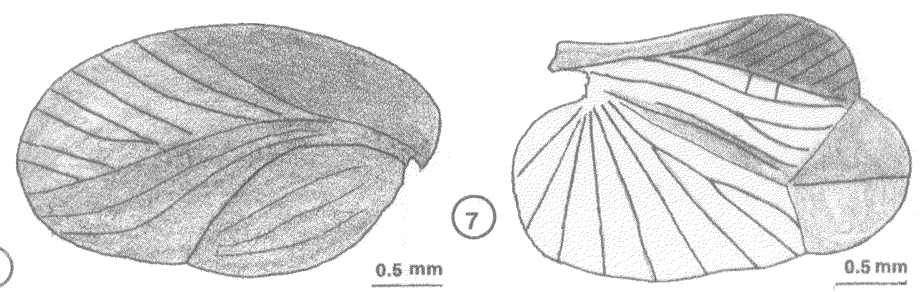

Figs. 1-7. Pseudoanaplectinia yumotoi Roth, from Sarawak (paratypes). 1,2,4,5, males; 6,7, female. 1. subgenital plate and genitalia (dorsal); 2. front leg (anterior surface; note only 2 distal spines on the ventral margin); 3 . ootheca removed from a female abdomen; the embryos are well developed and show segmentation; eyes are present but not visible in this view; 4. terminal abdominal segments (dorsal); 5 . subgenital plate (ventral); 6 . tegmen; 7 . hind wing.

Pairs of adult paratypes ( $(0$ and $९$ ) have been deposited in ANSP, HECO, NMVA, NRSS, and RNHL.

Description. Male: Less than $5 \mathrm{~mm}$ long (average, $4.0 \mathrm{~mm}$ ). Body in profile strongly convex. Head, pronotum, tegmina, and abdomen with widely spaced fine setae. Head almost completely 
hidden, eyes wide apart, interocular space greater than the distance between antennal sockets; fifth maxillary palpomere about twice as long as the fourth. Antennae short, not reaching beyond the middle of the abdomen, proximal segments stout, becoming more slender and filamentous distad; the antennae of most of the specimens were missing many segments and these were probably clipped off by the ants. Pronotum parabolic. Tegmina and wings (Figs. 6, 7) reduced, the former reaching to about the supraanal plate, wings slightly smaller. Hind wing with costal vein region enlarged, strongly arched; radial and media veins simple; cubitus vein with a single pseudocomplete branch that reaches the basal margin of the appendicular field (in most other cockroaches, complete branches reach the apical margin of the wing); the wing is folded longitudinally along the plical fold, and the appendicular field, which occupies about $30 \%$ of the length of the wing, is reflexed when the wing is at rest. (The relative length of the appendicular field is determined, when the wing is fully extended and flattened, by measuring the field from its base to apex and dividing this by the total length of the wing from the point of attachment to the apex of the appendicular field.) Legs short and stocky; forefemora with two relatively close distal spines on both ventral margins, genicular spine absent (Fig. 2); mid- and hindfemora with two to four (usually three) more widely separated distal spines, genicular spine present; foretibia about as long or shorter than all tarsomeres combined, midand hindtibiae slightly longer than the tarsi; pulvilli absent, tarsal claws symmetrical, ventral margins minutely serrated, the teeth contiguous and clumped together, arolia minute. Seventh abdominal tergum with a broad medial depression bearing some setae (Fig. 4; note the tergal gland area showing a few setae; a slide preparation reveals many more setae which are not visible in the pinned specimen); supraanal plate convexly rounded, entire. Subgenital plate asymmetrical, styles cylindrical, the left one slightly longer than the right one, interstylar margin weakly produced (Fig. 1). Genitalia as in Fig. 1: hook on the left side, curved hook portion sclerotised, with a preapical incision; median phallomere is an elongated rod, its distal region with setae; right phallomere consisting of several sclerites. Cerci greatly reduced, consisting of five segments, not reaching beyond the hind margin of the supraanal plate (Fig. 4). 
Female: Habitus similar to the male. Tegmina and wings usually reaching to about the sixth tergum. Supraanal plate convexly rounded reaching the convexly rounded hind margin of the subgenital plate. Subgenital plate not valvular.

Ootheca: A large number of females were pregnant and some of them (with stout abdomens) were dissected, each revealing a complete ootheca lying in the abdomen, showing that the species is ovoviviparous. The eggs are arranged in essentially two rows (Fig. 3 ) with their heads directed to the left. The number of eggs per ootheca varied (number of females in parentheses) from 3(2), 4(4), or 5(4). The size of the embryos varied, depending on the degree of their development, with the smallest being $1.5 \mathrm{~mm}$ long, and the largest $2 \mathrm{~mm}$ (Fig. 3). Segmentation is already present, as are eyes (not visible in the figure because of the orientation). The oothecal membrane is colorless, completely covers the eggs initially, and lacks a serrated keel and calcium oxalate crystals. As the eggs get larger, the two margins of the keel region become separated.

The fact that the eggs are enclosed in an oothecal membrane shows that they are first extruded and arranged in two rows, keel and head region upright, enclosed by a membrane, and then rotated $90^{\circ}$ (keel region directed to the left side) and retracted into the abdomen (Roth and Willis, 1958; Roth, 1970); they are not simply transferred directly into the uterus where they lie in a jumbled mass, as in some genera of Panesthiinae (Rugg and Rose, 1984). With so few eggs in an ootheca (e.g., when only three eggs are produced), it is possible that none of them actually protrude from the end of the abdomen and the egg case may be formed and rotated in the vestibule, without being exposed. Protrusion of eggs beyond the end of the abdomen during oothecal formation apparently depends on the size and number of eggs, and the size of the female. In a much larger viviparous cockroach, Diploptera punctata (Eschscholtz), there are only about a dozen initially small eggs in an ootheca; during oothecal formation few eggs protrude beyond the female's body, and protrusion occurs rather infrequently (Roth and Willis, 1955).

Color. Head brown with clypeus, labrum, maxillary and labial palps, and antennae pale. Legs and cerci pale. Tegmina brown. Hind wing with costal vein area dark, appendicular field lightly 
infuscated (Fig.7). Abdomen brown; glandular fossa on the male's seventh abdominal tergum yellowish brown.

Measurements $(\mathrm{mm})\left[\mathrm{N}=100^{\circ} 0^{\circ}\right.$ and $10 \%$ (shown in parentheses); averages in brackets]: Length, 3.8-4.1 [4.0] (3.8-4.1) [4.0]; pronotum length $x$ width, $1.1-1.3 \times 1.8-2.0$ [1.2 $\times 1.9](1.0-1.3 \times$ 1.8-2.0) [1.2 × 1.9]; tegmen length, 2.3-2.6 [2.5] (2.1-2.4) [2.3]; interocular width, 0.9 [0.9] (0.9) [0.9].

Nymphs: The immature specimens of both sexes resemble the adults except for the absence of tegmina and wings.

Etymology: The genus denotes the relationship, based on wing venation, male genitalia and subgenital plate, to some species that have been placed (by Princis) in the Anaplectinae (e.g., Anaplectella, Anaplectoidea, and Malaccina). The specific name is dedicated to Dr. Takakazu Yumoto, of the Center for Ecological Research, Kyoto University, who collected the material.

Comments: Large numbers of Pseudoanaplectinia live in association with an ant (Crematogaster sp.) on the epiphytic stag's horn fern, Platycerium coronarium (Koenig) Desv. (Yumoto, personal correspondence).

There are very few records of myrmecophilous cockroaches and these are mostly anecdotal (Roth and Willis, 1960; Hölldobler and Wilson, 1990). The polyphagid cockroach Myrmecoblatta wheeleri Hebard inhabits the nest of Solenopsis geminata (Fabricius) (Hebard, 1917) in Guatemala. It has also been taken in a nest of Camponotus abdominalis (F.) in Costa Rica (Fisk et. al, 1976), and with Camponotus abdominalis floridanus (Buckley) in Florida by Deyrup and Fisk (1984), who found them under a dead slash pine $\log$ in a scrubby flatwoods habitat. Myrmecophilous crickets (Myrmecophila sp.) occurred in the same nest. The ants did not try to carry off the cockroaches, which hid under bits of bark and in cracks of the dead tree. The cockroaches ran rapidly and withdrew their appendages under the body and adhered tightly to the substrate. Legs, antennae, and cerci generally showed no evidence of being damaged by the ants.

Probably the best known cockroach myrmecophile is Attaphila fungicola Wheeler, a Texas species that lives in the fungus cavities and tunnels made by the fungus growing ant Atta texana (Buckley). Wheeler (1900) originally thought that the cockroaches fed on the fungus but later (Wheeler, 1910) decided that they obtained 
nourishment by mounting and licking the backs of soldiers; the antennae of the cockroaches are always mutilated, probably when the ants are pruning their fungi. Moser (1964) found that the cockroaches respond positively to the ants' odor trail substance, and they also ride on the ant queens during mating flights. The cockroach's arolium is greatly developed and allows the blattellid to adhere firmly to the queen during swarming, thus facilitating the myrmecophile's dispersal (Brossut, 1976, fig. 3). Attaphila bergi Bolívar inhabits the nests of the ant Acromyrmex lundi in Argentina and Uruguay. The cockroach's antennae are always mutilated. The myrmecophile sits on the back, neck, or head of sexual individuals, and when they swarm it is carried out of the nests still attached to the host (Bolívar, 1901). Just how Pseudoanaplectinia is dispersed is unknown. Its small arolia indicate that it does not attach itself to the ants; although the female's wings are reduced it is possible that they are large enough to allow some flight and, if true, this may be their method of dispersal.

Wing venation and male genitalia of Pseudoanaplectinia are similar to and suggest a relationship to species of oviparous Anaplectella spp. (Roth, 1996b) but their leg armament and type of reproduction are markedly different. Attaphila fungicola is oviparous, has an ootheca that lacks a keel, contains about 6 eggs (Roth, 1970, fig. 21), and resembles the ootheca of $P$. yumotoi. It has been considered to be a polyphagid, but its ovaries and male genitalia are those of a blattellid; the male's genital hook is on the left side placing it in the Blattellidae: Blattellinae (McKittrick, unpublished observation). The two species can be separated as follows:

\begin{tabular}{|c|c|c|}
\hline Character & Attaphila fungicola & $\begin{array}{l}\text { Pseudoanaplectinia } \\
\text { yumotoi }\end{array}$ \\
\hline Reproduction & oviparous & ovoviviparous \\
\hline Cerci & unsegmented & segmented \\
\hline Arolia & very large & very small \\
\hline Tarsal claws & presumably simple* & serrated \\
\hline Tegmina \& wings & $\begin{array}{l}\text { (male) vestigial } \\
\text { (female) absent }\end{array}$ & $\begin{array}{l}\text { (male) reduced } \\
\text { (female) reduced }\end{array}$ \\
\hline Abdomen (male) & unspecialized & gland on T7 \\
\hline
\end{tabular}

*Neither Wheeler (1900) nor Hebard (1917) stated that the claws are serrated. 


\section{ACKNOWLEDGEMENTS}

I thank the Australian Biological Resources Study (ABRS) for partial financial support and Dr. Takakazu Yumoto of the Center for Ecological Research, Kyoto University, Otsu 520-01, Japan for sending me the specimens.

\section{Literature Cited}

Bolívar, I. 1901. Un nuevo ortóptero mirmecófilo Attaphila Bergi. Com. Mus. Nac. Buenos Aires 1:331-336.

Brossut, R. 1976. Étude morphologique de la blatte myrmécophile Attaphila fungicola Wheeler. Insectes Soc. 23:167-174.

Deyrup, M.,and Fisk, F. 1984. A myrmecophilous cockroach new to the United States (Blattaria: Polyphagidae). Entomol. News 95:183-185.

Fisk, W.F., Vargas, M., and Fallas, F. 1976. Notes on Myrmecoblatta wheeleri from Costa Rica (Blattaria: Polyphagidae). Proc. Entomol. Soc. Wash. 78:317-322.

Hebard, M. 1917. A new species of myrmecophilous blattid (Orthoptera; Blattidae; Corydiinae). Entomol. News 28:360-363.

Holldöbler, B. and Wilson, E.O. 1990. The Ants. Harvard Univ. Press, Cambridge, MA, $732 \mathrm{pp}$.

Moser, J.C.C. 1964. Inquiline roach responds to trail-marking substance of leaf-cutting ants. Science 143:1048-1049.

Roth, L.M. 1970. Evolution and taxonomic significance of reproduction in Blattaria. Ann. Rev. Entomol. 15:75-96.

Roth, L.M. 1971. Additions to the oothecae, uricose glands, ovarioles, and tergal glands of Blattaria. Ann. Entomol. Soc. Amer. 64:127-141.

Roth, L.M. 1982. Ovoviviparity in the blattelid cockroach, Symploce bimaculata (Gerstaecker) (Dictyoptera: Blattaria: Blattellidae). Proc. Entomol. Soc. Wash. 84:277-280.

Roth, L.M. 1984. Stayella, a new genus of ovoviviparous cockroaches from Africa (Dictyoptera: Blattaria, Blattellidae). Entomol. Scand. 15:113-139.

Roth, L.M. 1989. Sliferia, a new ovoviviparous cockroach genus (Blattellidae) and the evolution of ovoviviparity in Blattaria (Dictyoptera). Proc. Entomol. Soc. Wash. 91:441-451.

Roth, L.M. 1996a. Cockroaches from the Seychelles Islands (Dictyoptera: Blattaria). Jour. African Zool. 110:97-128.

Roth, L.M. 1996b. The cockroach genera Anaplecta, Anaplectella, Anaplectoidea, and Malaccina (Blattaria, Blattellidae: Anaplectinae and Blattellinae). Orient. Ins. 30:301-372.

Roth, L.M., and Willis, E.R. 1955. Intra-uterine nutrition of the "Beetle-roach" Diploptera dytiscoides (Serv.) during embryogenesis, with notes on its biology in the laboratory (Blattaria: Diplopteridae). Psyche 62:55-68.

Roth, L.M., and Willis, E.R. 1958. An analysis of oviparity and viviparity in the Blattaria. Trans. Amer. Entomol. Soc. 83:221-238.

Roth, L.M., and Willis, E.R. 1960. The biotic associations of cockroaches. Smith. Misc. Coll. 141:1-470.

Rugg, D., and Rose, H.A. 1984. The taxonomic significance of reproductive behaviour in some Australian cockroaches (Blattodea: Blaberidae). Jour. Aust. Entomol. Soc. 23:118. 
Wheeler, W.M. 1900. A new myrmecophile from the mushroom gardens of the Texan leaf-cutting ant. Amer. Natur. 34:851-862.

Wheeler, W.M. 1910. Ants: their structure, development and behavior. Columbia Univ. Press, New York, 663 pp. 

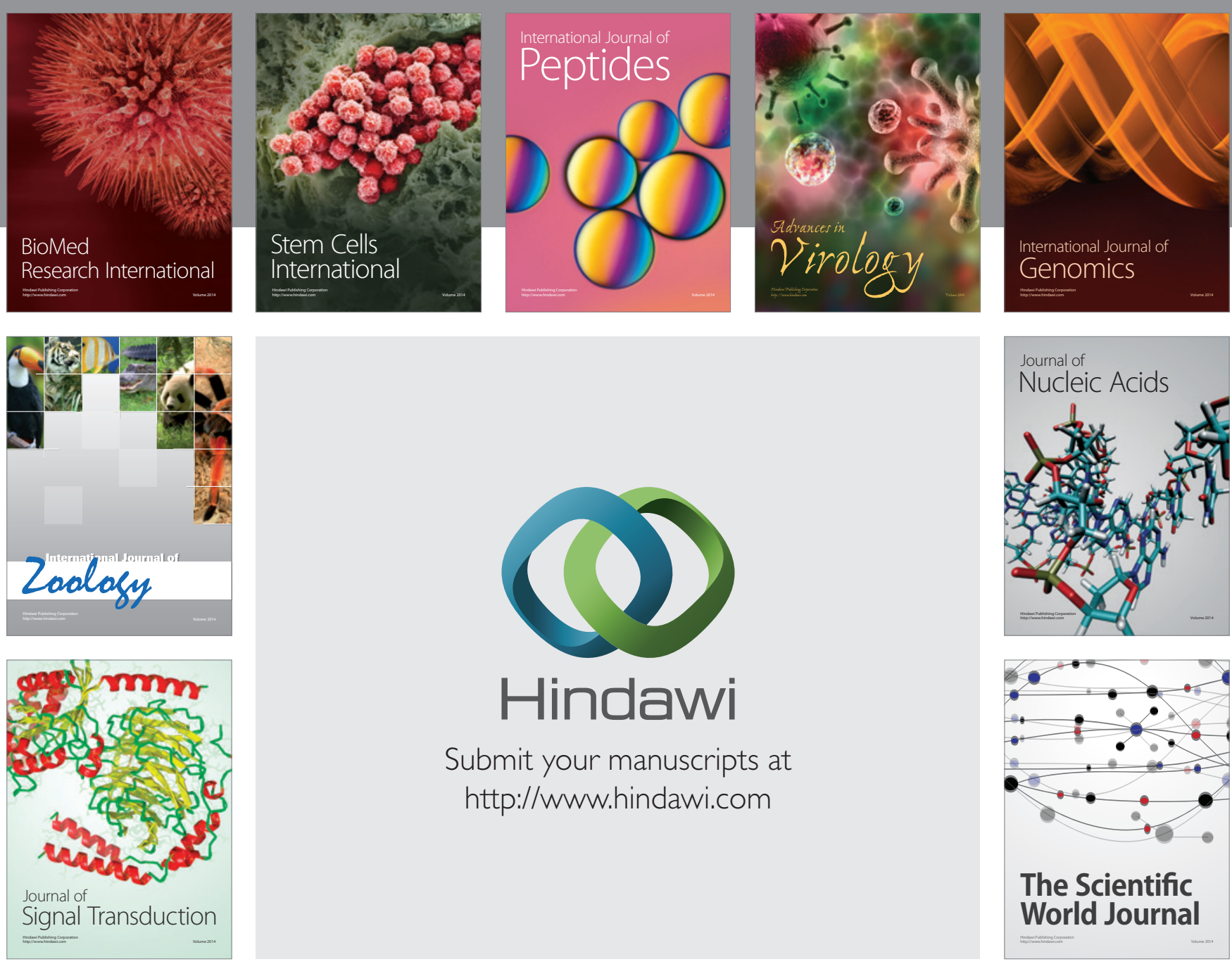

Submit your manuscripts at

http://www.hindawi.com
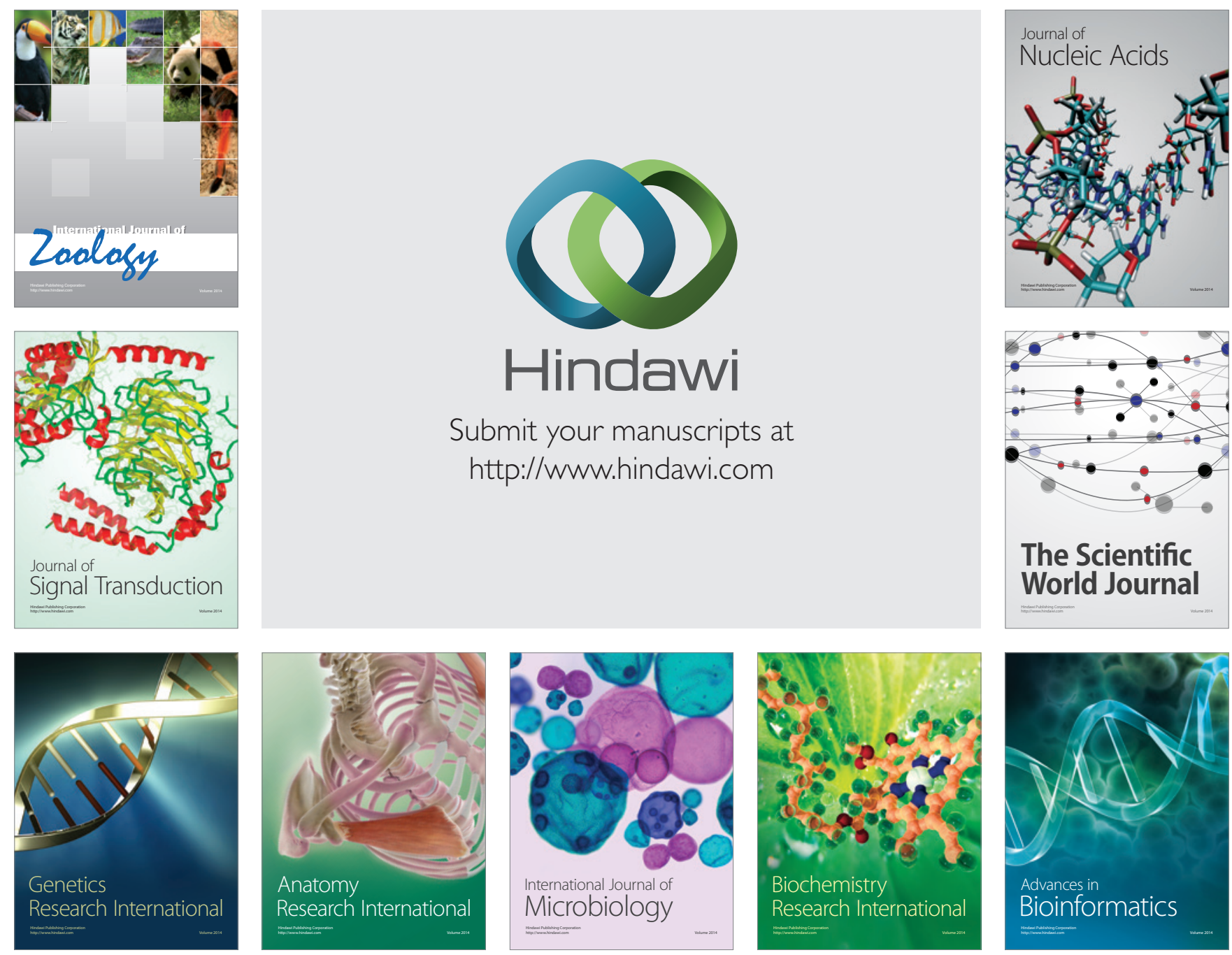

The Scientific World Journal
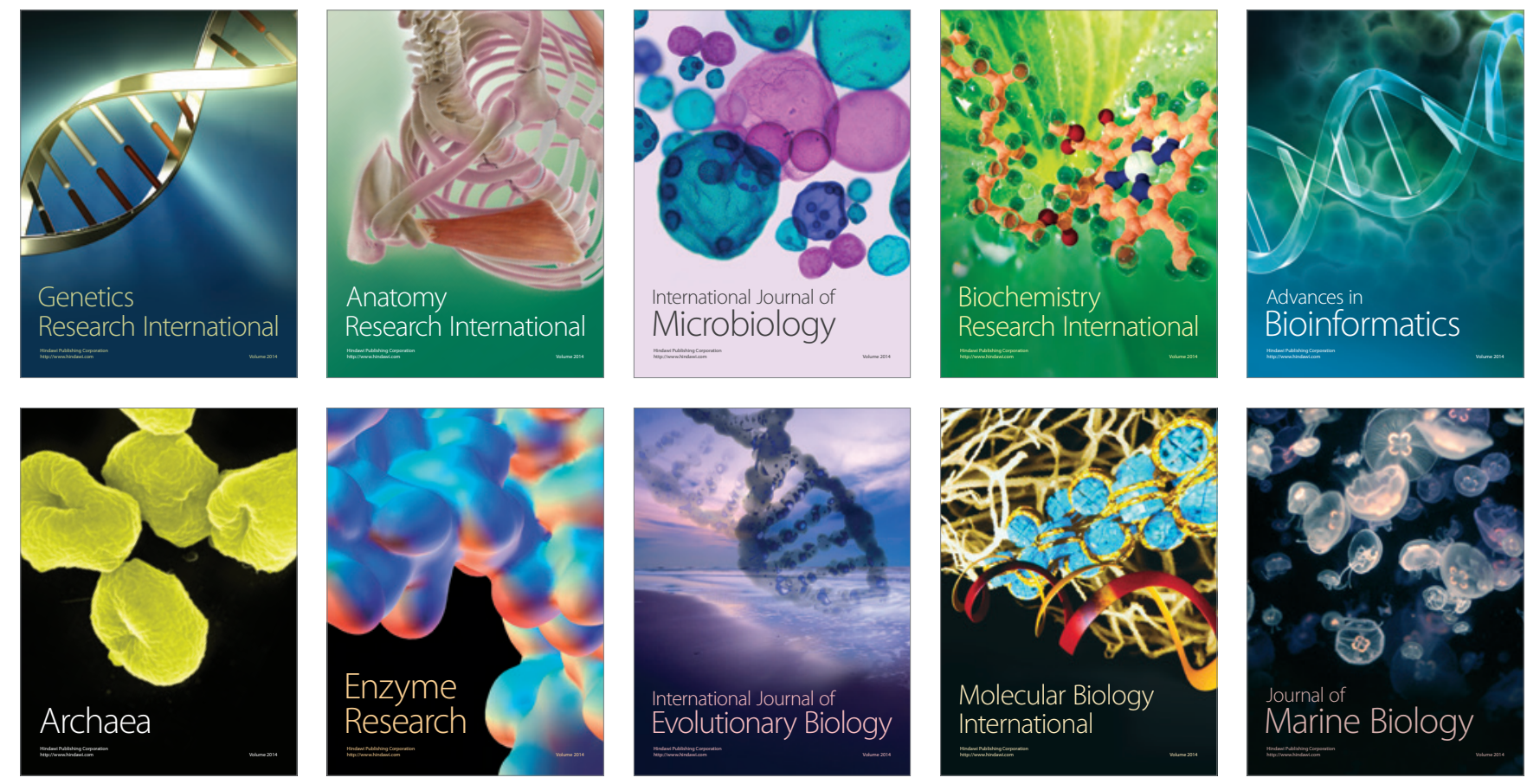